\title{
Vertical distribution of limnetic copepods in relation to the temporal variability of thermocline depth in a tropical caldera lake
}

\author{
Iris Hyacinth Alonso ${ }^{1}$, Camille M. Pastrana ${ }^{1}$, Janine F. Pacia ${ }^{1}$, \\ Carla Mae Lois G. Piscoso ${ }^{1}$, Dino T. Tordesillas ${ }^{* 2,3}$, E Rey Donne S. Papa ${ }^{1,2,4}$ \\ ${ }^{1}$ Department of Biological Sciences, College of Science; ${ }^{2}$ Graduate School; ${ }^{3}$ Senior High School; \\ ${ }^{4}$ Research Center for the Natural and Applied Sciences, University of Santo Tomas, \\ Manila 1015 , Philippines
}

\begin{abstract}
The thermocline depth of Lake Taal and its effect on the vertical migration patterns of two limnetic copepod species during the intermediate monsoon season were investigated. Most of the diel vertical migration patterns were normal. Reverse DVM, which was exhibited by some adult copepods, was observed when wind speed changed during the sampling period. Lake Taal started to exhibit atelomixis as the wind speed started to fluctuate. Diel vertical migration of the copepods was affected by the prevailing atelomixis.
\end{abstract}

Keywords: atelomixis, DVM, intermediate monsoon, Lake Taal, Arctodiaptomus dorsalis, Thermocyclops crassus, zooplankton

\section{INTRODUCTION}

Lake stratification and vertical mixing patterns have allowed researchers to determine species abundance and turnover [1]. Thermocline depth, as an indicator of stratification, varies depending on the light and heat penetration from the sun, according to the seasonal and non-seasonal changes in weather conditions [2]. In the Philippines, the monsoon seasons influence weather conditions as manifested by shifts in wind direction and the amount of rainfall that can cause shifts in thermocline depth that result to lake mixing. There are four known monsoon seasons occurring in the Philippines - the

*To whom correspondence should be addressed: dttordesillas@ust.edu.ph northeast (December-March), southeast (AprilMay), southwest (June-September) and intermediate (October-November) monsoons. The variations in thermocline depth in relation to the monsoons and their corresponding wind and rain patterns have not been recorded for Lake Taal, although Lewis [3] reported the occurrence of atelomixis in relation to such factors in Lake Lanao.

Atelomixis is a form of lake stratification that indicates external factors such as the climate, and internal factors such as the lake's biodiversity. Lewis [3] defined atelomixis as a major increase in the thickness of the mixed layer in response to non-seasonal weather changes while the lake is stratified. He stated that the features of heat distribution are partly due to a 
seasonal temperature minimum and nonseasonal weather changes. With the Philippines being among the countries most vulnerable to climate change, having cyclones, landslides, floods, and droughts as its dominant hazards [4], it is supposed to have undergone changes in stratification and mixing patterns as well. Copepods are most known to undergo extensive migration patterns due to their need to find food, avoid predators, and adapt according to their temperature-dependent metabolic rates above and below the thermocline [5]. Migration because of visual predator avoidance is highly influenced by light according to the diel cycle, lunar cycle, cloud cover, and water turbidity. The diel cycle causes zooplankton to descend in the day and ascend at night. Ascension at night varies according to the lunar cycle, as a full moon would mean a relatively high level of illumination, rendering larger zooplankton vulnerable to predation [6], thus a lower migration amplitude. Cloud cover and turbidity caused by wind or rain can alter the intensity of the light, whether from the sun or moon, that reaches the lake which provides weak and momentary concealment for large zooplankton [7].

Arctodiaptomus dorsalis (Marsh, 1907) and Thermocyclops crassus (Fischer, 1853) are the two most common and dominant copepod species inhabiting Lake Taal [8]. Of the two, A. dorsalis is an invasive species that has driven other calanoid species out of their native habitat. It is also the largest copepod in Lake Taal [9]. Thermocyclops crassus, on the other hand, is a cosmopolitan species, which is a raptorial feeder that consumes larger blue-green algae as observed in Lake George, Uganda [10]. This species was observed in Lake Taal and found to have dominated other species under Order Cyclopodia $[8,11]$. The dominance, abundance and behavioral history of these two species make them practical models for DVM investigation. Migration patterns, though common for zooplankton in any lake ecosystem, has not been fully investigated in Philippine lakes, nor has it been analyzed thoroughly in relation with thermocline depth. Taking this into account, the researchers aimed to determine the changes in thermocline depth in Lake Taal due to atelomixis during the intermediate monsoon season (October to November), and its relationship with the distribution and diel vertical migration patterns of the limnetic copepods $A$. dorsalis and T. crassus.

\section{EXPERIMENTAL}

Study area. Sampling was conducted at the eastern portion of the south basin of Lake Taal, near the town of Kinalaglagan, Mataas na Kahoy, Batangas, Philippines (Fig. 1). Lake Taal (135'$\left.14^{\circ} 05^{\prime} \mathrm{N}, 120^{\circ} 55^{\prime}-121^{\circ} 105^{\prime} \mathrm{E}\right)$, is the third largest lake in the Philippines. It is a meso to eutrophic caldera lake with a surface area of $268 \mathrm{~km}^{2}$ with mean and maximum depths of $90.4 \mathrm{~m}$ and $198 \mathrm{~m}$. It was formed after a series of volcanic explosions that separated the lake from the rest of the South China Sea [12]. Lake volume is $21,426 \times 10^{6} \mathrm{~m}^{3}$ with a $682.8 \mathrm{~km}^{2}$ catchment area $[13,14]$. It is home to the worlds' lowest active volcano which partially separates the north and south basins of the lake. Lake water is neutral to slightly alkaline with a $\mathrm{pH}$ that ranges from 7.2 to 8.9 with a high conductivity $[12,14,15]$.

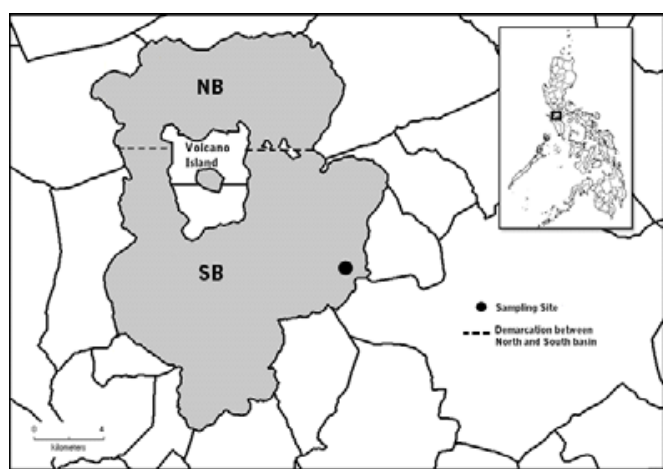

Figure 1. Map of Lake Taal showing the sampling site. Inset map shows the location of Lake Taal in the Philippines 
Sample collection. The zooplankton were collected at $13^{\circ} 59^{\prime} 08.5^{\prime \prime} \mathrm{N} 121^{\circ} 04^{\prime} 56.3^{\prime \prime} \mathrm{E}$ at 12:00 noon and 12:00 midnight for two consecutive days (November 8-9, 2014 - representing the intermediate monsoon season) using a $38-\mathrm{L}$ Schindler-Patalas plankton trap. Zooplankton were taken from the limnetic zone of the lake with a maximum depth of $30 \mathrm{~m}$. Samples were collected at $5 \mathrm{~m}$ intervals from the deepest portion of the lake $(30 \mathrm{~m})$ to subsurface $(>0 \mathrm{~m})$. An $80 \mathrm{~mm}$ mesh size plankton net was used to filter the trap's contents.

Temperature loggers. The HOBO Pendant Temperature/Light Data Loggers were used to record the lake's vertical temperature profile. There were seven sensors attached to a $30 \mathrm{~m}$ rope connected to a buoy. One sensor was attached near the surface (at $0.5 \mathrm{~m}$ ) while succeeding sensors were located at $5 \mathrm{~m}$ intervals. These sensors were deployed in the south basin of the lake simultaneous with the collection of zooplankton. After the sampling, the data was collected from the loggers through the software, HOBOware Pro. An optic USB base station was used for the data transfer. The temperature data was then compared to the weather profile at that time according to records taken by DOST-PAGASA.

Specimen processing. The collected zooplankton were fixed in $70 \%$ ethanol $(\mathrm{EtOH})$ and stored in sample bottles. The collected samples were processed after 10 days to ensure that the fixative had taken effect. The samples were then stained with $70 \%$ EtOH mixed with Rose Bengal dye for easier identification of specimen observed under the microscope.

Sample classification and counting. The density of zooplankton was determined by counting zooplankton in $1 \mathrm{~mL}$ Sedgewick-Rafter sub samples [16]. Five replicates were counted for every sample. The copepods observed were identified to species level and corresponding life stage as follows: A. dorsalis adult male, $A$. dorsalis adult female, A. dorsalis copepodite, A. dorsalis nauplii, T. crassus adult male, $T$. crassus adult female, T. crassus copepodite, and T. crassus nauplii. Cladocerans and rotifers counted were classified as "others." Counting was done under low power objective.

Data analysis. DAI or the depth of average individual was computed for noon and midnight. This was then used to determine migration amplitude (A) which is the difference between the DAI of each species at noon and midnight. Positive values are classified as positive DVM which indicates upward migration, while negative values were noted as negative DVM or a downward migration. Difference in migration amplitude will be tested between A. dorsalis and T. crassus species using the two-sample Kolmogorov-Smirnov (K-S) test. Percent abundance $(\% \mathrm{Ab})$ per depth was determined. All statistical tests were performed using the PAST software Version 2.17 and all graphs were generated with the use of SigmaPlot software [5].

\section{Results}

The temperature recorded in the two days of sampling ranges from $27.5^{\circ} \mathrm{C}$ to $31.0^{\circ} \mathrm{C}$ with the sampling site having a maximum depth of $30 \mathrm{~m}$. For both noon samplings, there were relatively high temperatures from the surface to $5 \mathrm{~m}$, represented by a positive slope, which marked the thermocline layer. The thermocline was not as pronounced during the second day compared to the first (Fig. 2). There was no thermocline observed during midnight for both sampling days. Furthermore, there were higher temperatures noted for $30 \mathrm{~m}$ compared to the surface; highest rainfall was recorded during midnight of November 8, 2014 at $1.2 \mathrm{~mm}$ (Fig. 2).

The variations in the depth distribution of $T$. crassus and $A$. dorsalis in the water column during noon and midnight point to the occurrence of diel vertical migration (DVM) as 


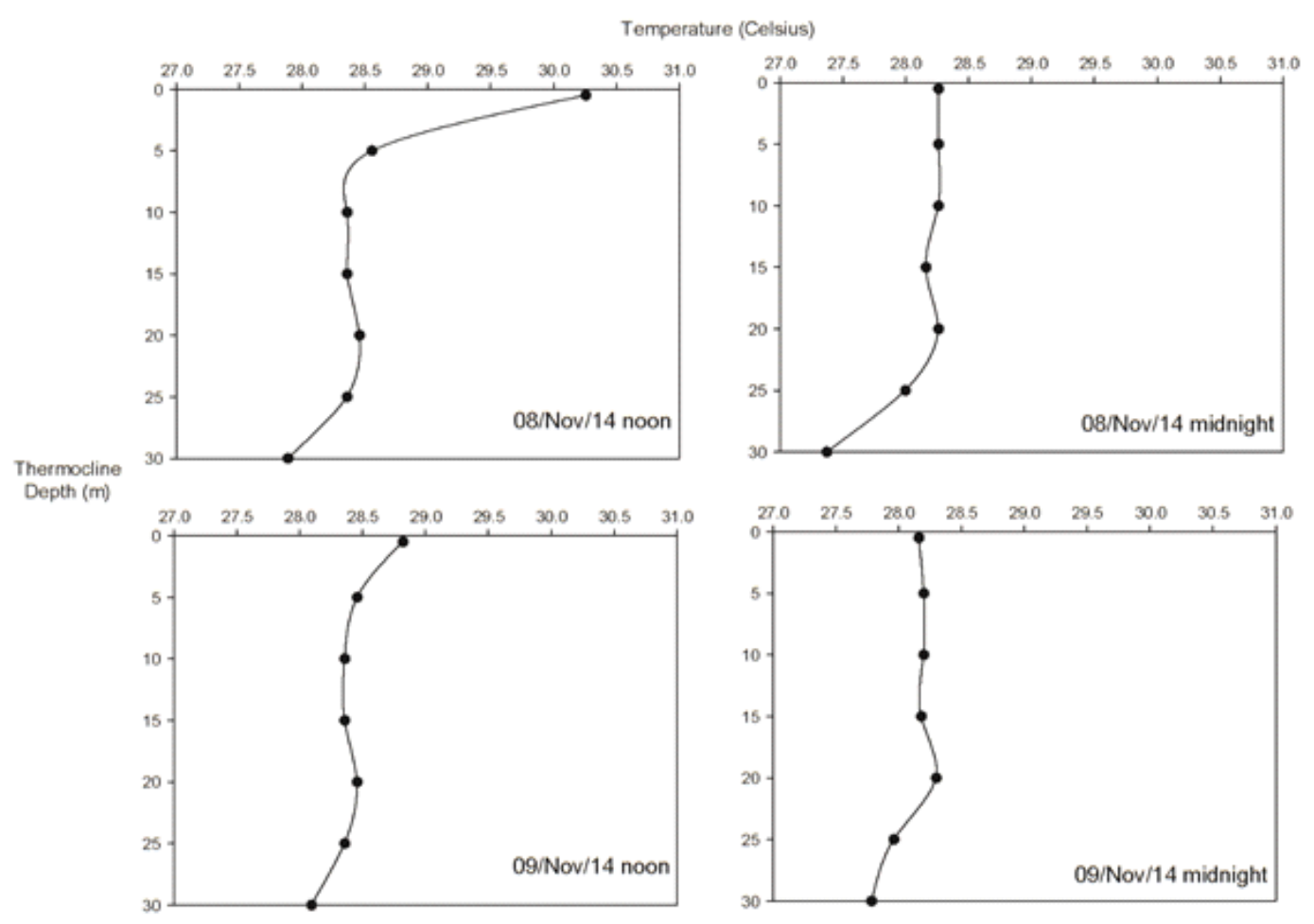

Figure 2. Thermocline depth data of Lake Taal (November 8-9, 2014)

most formed aggregations and moved closer to the surface of the lake at night time and go back to the deeper parts of the water column during daytime. A comparison of mean population depths using DAI values between the first and second days together with an analysis of the changes in the vertical temperature profile revealed that mean population depths were lower during the first day as compared to the second, which coincided with the occurrence of a steeper thermocline (Fig. 3). All life stages of $T$. crassus had higher migration amplitudes during the first day compared to the second day. However, a more extreme pattern occurred for the adult male $T$. crassus which showed positive DVM during the first day but shifted to reverse DVM for the second sampling day. Adult female A. dorsalis exhibited negative migration amplitudes for both days, but was notably more intense during the first day (Fig. 4). Adult male and copepodite A. dorsalis both had positive DVM but the second day migration amplitudes were higher than the first day. These patterns of vertical migration of both species had no significant differences in both the November 8 (Two-sample K-S test, $\mathrm{D}=0.75, \mathrm{p}<0.05$ ) and November 9 (Two-sample K-S test, $\mathrm{D}=0.25, \mathrm{p}<$ 0.05 ) sampling dates.

Lastly, the percentage distribution of the life stages of $A$. dorsalis and $T$. crassus shows that most of its life stages have higher densities in the deeper portions of the water column during noon followed by higher densities in the surface waters. Some depth layers were unoccupied during noon, which was especially noticeable among adults of both species, which preferred greater depths. During midnight, this pattern changes as the adult copepods were found nearer to the surface but were more distributed 

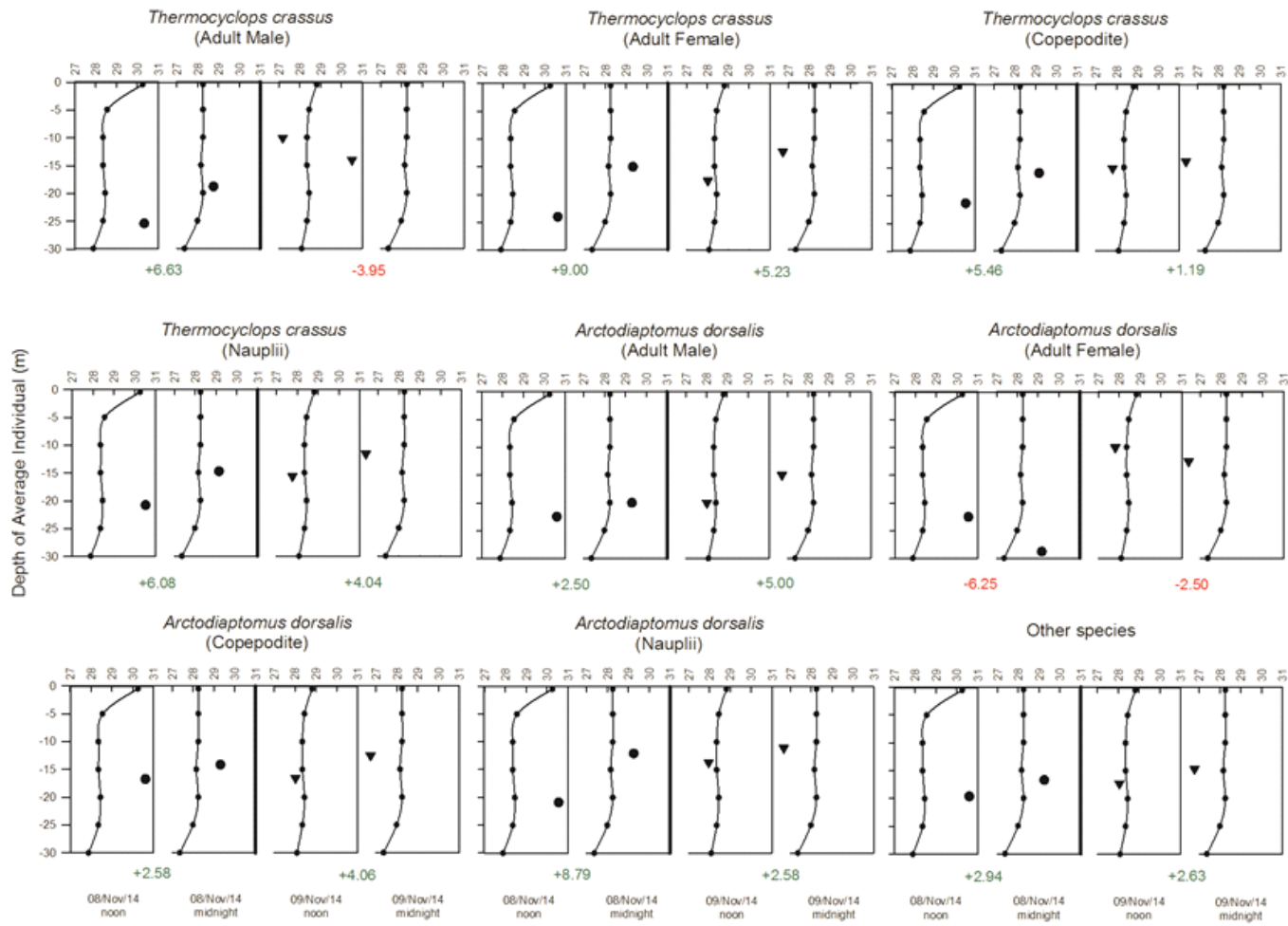

Figure 3. Depth of Average Individual (DAI) of limnetic copepods in Lake Taal (•-November 8, 2014 sampling, $\boldsymbol{\nabla}$-November 9, 2014 sampling)

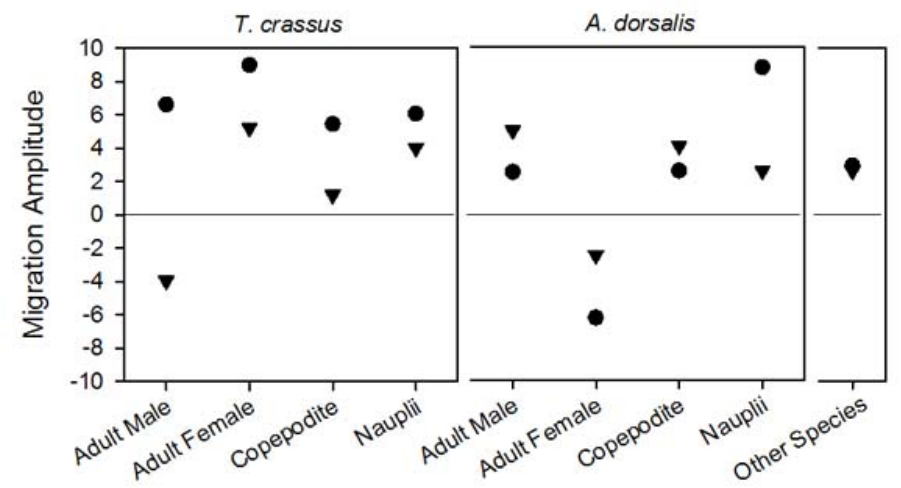

Figure 4. Migration Amplitude (A) of limnetic copepods per species and life stage $(\bullet-N o v e m b e r$ 8, 2014 sampling, $\boldsymbol{\nabla}$-November 9, 2014 sampling)

across depths (Fig. 5). The differences in the depth distribution among smaller life stages (i.e. copepodites and nauplii) as well as the other species counted were not as pronounced as the adult $T$. crassus and $A$. dorsalis.

\section{Discussion}

Except for the adult $A$. dorsalis males, both species exhibited normal DVM as previously defined [17] and takes advantage of the brief 

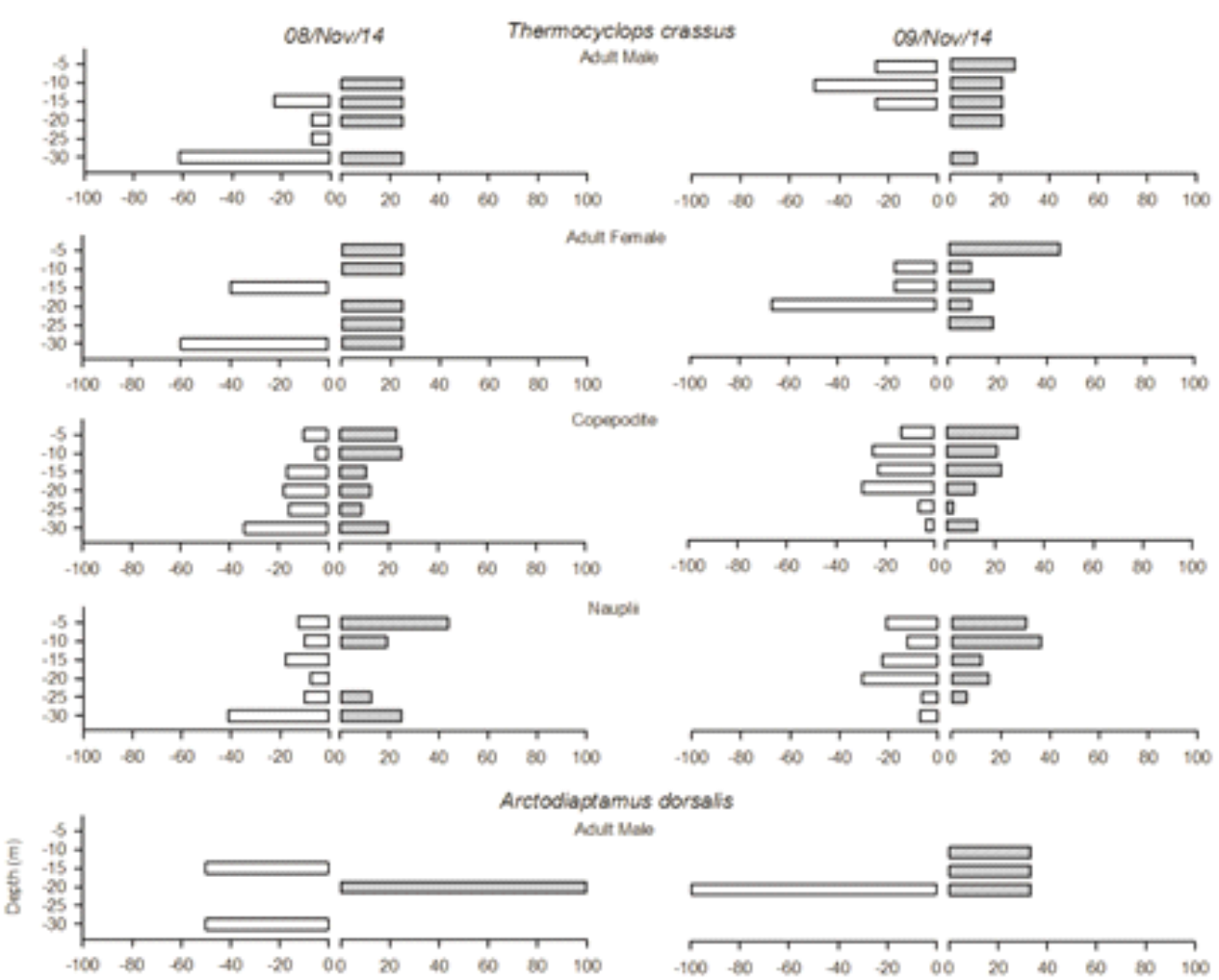

aptamus chorsalis
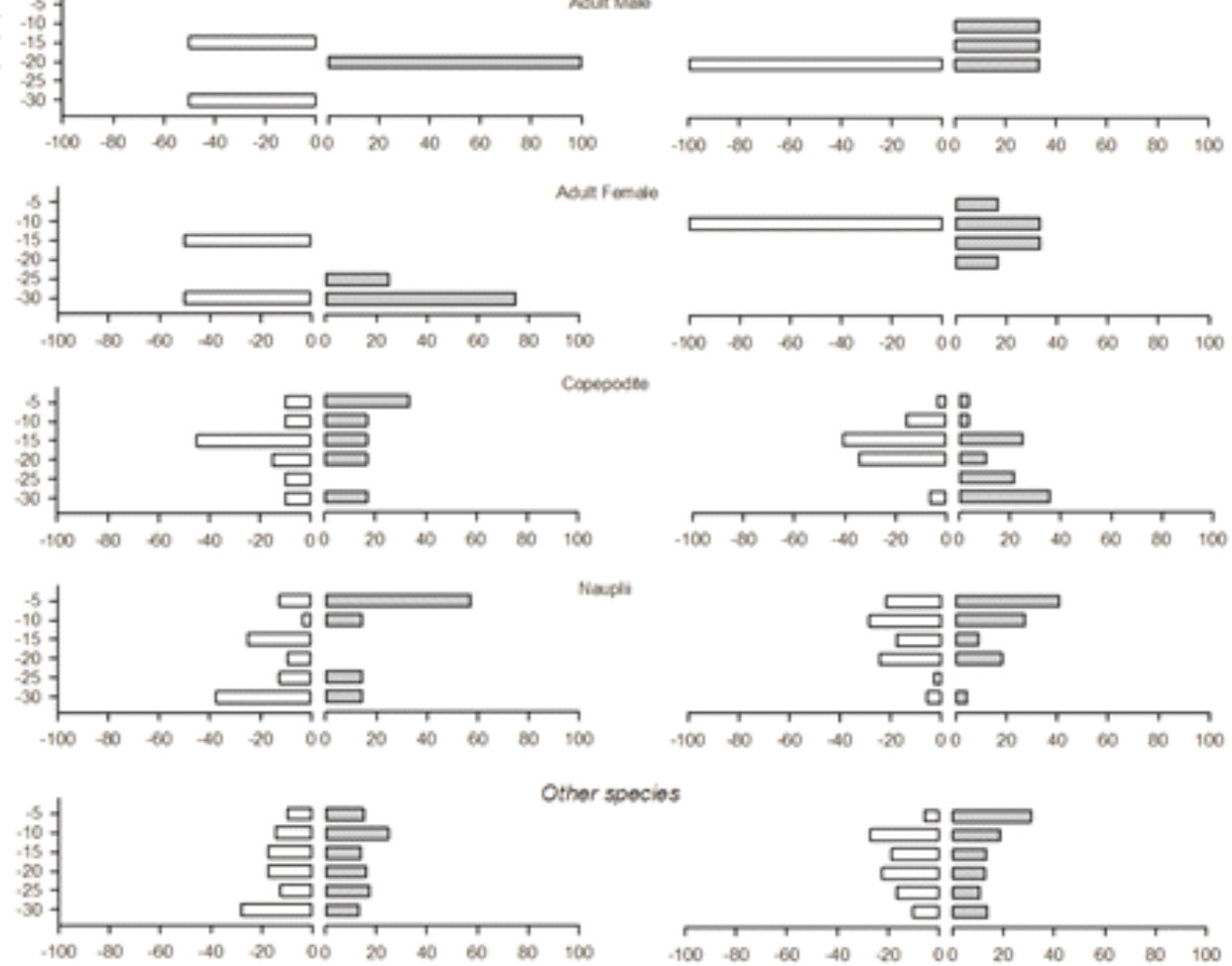

Figure 5. Percent Abundances (\%Ab) of the different life stages of Thermocyclops crassus and Arctodiaptomus dorsalis in different depth layers sampled. Open bars represent samples collected at noon while shaded bars represent samples collected at midnight 
period when the surface water is still warm and the light from the sun has disappeared [18]. Warmth and darkness allow zooplankton to metabolize faster without the pressure from visual feeders. At the onset of the full moon, there is complete darkness for one to three hours before the moon. Because of this period of complete darkness, zooplankton ascends to the surface and are suddenly exposed to predators when the moon appears [19]. This study was done on the days following the full moon at 93$98 \%$ illumination. This typical behavior was observed where copepods exhibited positive diel migration, except for some adults. This natural entrapment happens at a faster rate when wind is stronger and a full moon is present, eliminating warmth and darkness, which is not ideal for plankton but ideal for predators like the Sardinella tawilis which is a dominant zooplanktivore in Lake Taal [13].

The upward shift in their DAI as a population from November 8 to November 9, 2014 indicated that the copepods did not seem to return to their original noontime or nighttime depths due to the increase in average wind speed from $4 \mathrm{~m} / \mathrm{s}$ to $5 \mathrm{~m} / \mathrm{s}$ and the corresponding changes in the thermocline depth during the two dates mentioned above. Wind speed data recorded every $3 \mathrm{~h}$ showed that wind speed during the hours leading to noon of November 8 were consistent at $5 \mathrm{~m} / \mathrm{s}$, while windspeed prior to midnight fluctuated from $4 \mathrm{~m} / \mathrm{s}$ to $2 \mathrm{~m} / \mathrm{s}$, which coincided with the initial signs of atelomixis formation. It continued to fluctuate from $2 \mathrm{~m} / \mathrm{s}$ to $4 \mathrm{~m} / \mathrm{s}$ before noon of November 9 and lastly from $5 \mathrm{~m} / \mathrm{s}$ to $1 \mathrm{~m} / \mathrm{s}$ before midnight. Our data shows that atelomixis may not only be caused by non-seasonal weather changes, but by the abruptness of such changes happening within a given period. Atelomixis forms as the mixed layer thickens making it isothermic, a layer of quasi-uniform temperature represented in Figure 4 by horizontal slopes [20] pushing the thermocline downwards. According to [3], the wind can cause the thermocline to go beyond the $30 \mathrm{~m}$ depth.

The thermocline depth depends on the input of solar radiation on surface water, and degree of vertical mixing brought about by wind speed and wave action. Since Lake Taal is a tropical lake, there is a constant input of solar radiation in the water surface all year round. The potential influence of thermal vents as heat sources from below, make the thermocline a permanent feature, but its depth and position are highly variable $[3,16]$.

Vertical heterogeneity of zooplankton is induced by the light gradient on the lake. However, unlike tropical Lake Taal, shallow temperate lakes like Lake Vela in the Mediterranean, vertical heterogeneity of zooplankton is not established during autumn where water is in its turbid phase [18], showing that light and turbidity can affect zooplankton distribution. Another previous on Lake Nagada, Papua New Guinea concluded that responses to light stimuli depend on sex and life stage [21]. Migration was said to be more pronounced at the adult stage level, and in females. This is parallel to the results of this study on Lake Taal where the adult female $A$. dorsalis and adult male $T$. crassus were observed to have a negative DVM as their size might have affected the response of these species to their respective temperature-dependent metabolic rates above and below the thermocline [5].

Adult females are also known to exhibit negative phototaxis and are more sensitive to environmental changes [22]. The A. dorsalis adult female was consistent in its reverse migration pattern because of its relatively large size, as it is the largest copepod species in Lake Taal [5] together with the fact that female copepods are generally larger than males, making them more visible to predators. Since the study was done during a 93-96\% full moon with partial cloud cover, there is still illumination on the lake to cause said negative migration as 
the zooplankton were driven to deeper and less illuminated depths to avoid predation $[6,19]$.

Compared to the study of Battes and Momeu [23] on Lake Stiucii in Romania where they concluded that adult copepods showed normal DVM from day to night with low migration amplitudes and where the most important cause for DVM being predation pressure, the adult copepods of Lake Taal were found to exhibit a reverse DVM even though the cause for the migration is the same. The difference in DVM direction would be due to the predation of zooplankton by fish and Chaoborus larvae in Lake Stiucii which are tactile predators that live in the hypolimnetic layer.

A general trend shows that $T$. crassus exhibited a decrease in migration amplitude from day 1 to day 2, while A. dorsalis exhibited the opposite. This may be due to the difference in their size, as calanoids are larger than cyclopoids and have the ability to swim faster amidst lake mixing [24], as a response to the changing thermocline depths, as influenced by the shifts in windspeed on both days.

This research is the first attempt to determine thermocline depth and its relationship to two dominant limnetic zooplankton species in their different life stages, namely, A. dorsalis and $T$. crassus, in Lake Taal. The study was able to document the occurrence of atelomixis during the intermediate monsoon season, which played a vital role in diel vertical migration as well as depth distribution of $A$. dorsalis and T. crassus. The study also noted a reverse diel vertical migration for adult female $A$. dorsalis and male T. crassus which was caused by abrupt changes in the thermocline, however, over-all DVM patterns were similar among the different life stages of these two species. Other species (belonging to Cladocera and Rotifera) performed weaker migrations compared to these two copepods. These results highlight the role of the unique set of environmental cues in Lake
Taal and their role in determining the behavioral patterns among the organisms living in it.

\section{ACKNOWLEDGMenTS}

We would like to thank Jonathan Carlo Briones and Milette Mendoza for the statistical analyses and DOST-PAGASA for providing the weather data. R.D.S. Papa was supported by grants from the UST Research Center for the Natural and Applied Sciences and the Partnerships for Enhanced Engagement in Research (PEER) Science Grant awarded by the US National Academy of Science and USAID (Sub Grant No. PGA-2000004881;AID-OAA-A-11-00012 20142016). D. T. Tordesillas was supported by a Philippine Department of Science and Technology- Accelerated Science and Technology Human Resource Development Program (DOST-ASTHRDP) Scholarship Grant.

\section{REFERENCES}

[1] Barbosa FAR \& Padisak J. The forgotten lake stratification pattern: atelomixis, and its ecological importance. Verhandlungen des Internationalen Verein Limnologie 2002; 28, 138-1395.

[2] Chan V \& Matthews R. Using the generalized F distribution to model limnetic temperature profile and estimate thermocline depth. Ecological Modelling 2004; 188(2-4), 374-385.

[3] Lewis WJrM. The thermal regime of Lake Lanao (Philippines) and its theoretical implications for tropical lakes. Limnology and Oceanography 1973; 18, 200-217.

[4] Yusuf AA \& Francisco HA. Climate Change Vulnerability Mapping for Southeast Asia. Economy and Environment Program for Southeast Asia, p. 32. 2009.

[5] Papa RDS, Mamaril AC, Zafaralla MT, \& Eckmann R. Preliminary observations on the diel vertical migration of crustacean zooplankton in aquaculture and Aquaculture-free Areas of Lake Taal, Philippines. Pp. 82-94 In: Aralar MLC, Borja AS, Palma AL, Mendoza MM, Ocampo PC, Manalili EV, \& Darvin LC (Eds.) LakeCon2011: Building on the pillars of Integrated Lake Basin Management (Second National Congress on Philippine Lakes), p. 337. (Los Baños, Laguna: 
PCAARRD-DOST, 2013. (Summary of Proceedings No. 1/2013)

[6] Hernandez-Leon S, Almeida C, Yebra L, Aristegui J, Fernandez de Puelles ML, \& Garcia-Braun J. Zooplankton abundance in subtropical waters: Is there a lunar cycle?. Scientia Marina 2001; 65(1), 59-63.

[7] Hays GC, Warner AJ, \& Proctor CA. Spatiotemporal patterns in the diel vertical migration of the copepod Metridia lucens in the northeast Atlantic derived from the continuous plankton recorder survey. Limnology and Oceanography 1995; 40(3), 496-475.

[8] Papa RDS, Li H, Tordesillas D, Han B, \& Dumont HJ. Massive invasion of Arctodiaptomus dorsalis (Copepoda, Calanoida, Diaptomidae) in Philippine lakes: a threat to Asian zooplankton biodiversity? Biological Invasions 2012a; 14, 2471-2478.

[9] Papa RDS, Tordesillas DT, \& Mamaril ASrC. An updated taxonomic account of limnetic crustacean zooplankton of Lake Taal, Philippines. Philippine Journal of Science 2012b; 141(2), 253-262

[10] Talling JF \& Lemoalle J. Ecological Dynamics of Tropical Inland Waters, 441pp. (London: Cambridge University Press, 1998).

[11] Amarasinghe PB, Ariyarantne MG, Chitapalapong $\mathrm{T}$, \& Vijverberg J. Production, biomass and productivity of copepods and cladocerans in tropical Asian water bodies and the carrying capacity for zooplanktivorous fish. In: Schiemer F, Simon D, Amarasinghe US, \& Moreau J (Eds.) Aquatic ecosystems and development: Comparative Asian perspectives (Biology of Inland Waters Series), pp. 173-194. (Leiden, The Netherlands: Backhuys Publishers, 2008).

[12] Ramos EG. Origin and geologic features of Taal Lake, Philippines. Aquatic Ecosystem Health \& Management 2002; 5(2), 155-162.

[13] Papa RDS, Pagulayan RC, \& Pagulayan AEJ. Zooplanktivory in the Endemic Freshwater Sardine, Sardinella tawilis (Herre 1927) of Taal Lake, the Philippines. Zoological Studies 2008; 47(5), 535-543.

[14] Perez T, Enriquez EE, Guerrero RIIID, Simon D, \& Schiemer F. Catchment characteristics, hydrology, limnology and socio-economic features of Lake Taal, Philippines. In: Schiemer F, Simon D, Amarasinghe US, \& Moreau J (Eds.) Aquatic ecosystems and development: Comparative Asian perspectives (Biology of Inland Waters Series), pp 63-80. (Leiden, The Netherlands: Backhuys Publishers, 2008).
[15] Zlotnicki J, Sasai Y, Toutain P, Villacorte EU, Bernard A, Sabit JP, Gordon JM, Corpuz EG, Harada M, \& Punongbayan JT. Combined electromagnetic, geochemical and thermal surveys of Taal Volcano (Philippines) during the period 2005-2006. Bulletin of Volcanology 2009; 71, 29-47

[16] Papa RDS, Zafaralla MT, \& Eckmann R. Spatiotemporal variation of the zooplankton in a tropical caldera lake with intensive aquaculture (Lake Taal, Philippines). Hydrobiologia 2011; 664, 119 133.

[17] Hays GC, Leievre D, \& Warner AJ. Long-term changes in the diel vertical migration behaviour of zooplankton. Marine Ecology Progress Series 1996; 141, 149-159.

[18] Ringelberg J. The photobehaviour of Daphnia spp. as a model to explain diel vertical migration in zooplankton. Biological Reviews 2007; 74(4), 397-423.

[19] Gliwicz ZM. A Lunar Cycle in Zooplankton. Ecology 1986; 67(4), 883-897.

[20] Ahlbeck I, Holliland PB, Hansson S, \& Westlund E. Ontogenetic and seasonal diel vertical migration amplitudes of the calanoid copepods Eurytemora affinis and Acartia spp. in a coastal area of the northern Baltic proper". Journal of Plankton Research 2012; 34(4), 298-307.

[21] de Meester LD \& Vyverman W. Diurnal residence of the larger stage of the calanoid copepod Acartia tonsa in the anoxic monimolimnion of a tropical meromictic lake in New Guinea. Journal of Plankton Research 1997; 19(4), 425-434.

[22] Altin D, Alver MO, Batnes AS, Jensenn BN, Miljeteig C, Nordtug T, Olden AJ, \& Speed JDM. Sex and life stage dependent phototactic response of the marine copepod Calanus finmarchicus (Copepoda: Calanoida). Journal of Experimental Marine Biology and Ecology 2014; 451, 16-24.

[23] Battes KP \& Momeu L. Diel vertical distribution of planktonic microcrustaceans (Crustacea: Cladocera, Copepoda) in a natural shallow lake from Transylvania, Romania. Journal of Limnology 2014; 73(2), 236-246.

[24] Lampert $W$. The adaptive significance of diel vertical migration of zooplankton. Functional Ecology 1989; 3, 21-27. 